\title{
Identificação e comparação de espécies do gênero Eimeria Schneider, 1875 (Apicomplexa: Eimeriidae) oriundas de suínos através de um algoritmo morfológico*
}

\section{Identification and comparison of Eimeria species (Apicomplexa: Eimeriidae) from swines through a morphologic algorithm}

\author{
Paulo Roberto de Carvalho Filho, ${ }^{* *}$ Fabiana Valadão Massad, ${ }^{* *}$ Carlos Wilson Gomes Lopes,, ${ }^{* *}$ \\ Walter Leira Teixeira Filho, ${ }^{* \star *}$ Francisco Carlos Rodrigues de Oliveira ${ }^{* \star * *}$
}

\begin{abstract}
Resumo
Este artigo tem como objetivo identificar e comparar três espécies do gênero Eimeria em suínos criados em condições rústicas no município de Campos dos Goytacazes, estado do Rio de Janeiro com base na avaliação morfométrica tradicional e através de um algoritmo morfométrico previamente proposto. Os porcos dos quais foram coletadas fezes não tinham sinais clínicos característicos de eimeriose. Os oocistos encontrados foram separados morfologicamente em três tipos a partir das medidas dos diâmetros maior e menor dos oocistos esporulados. Foram encontradas E. neodebliecki, E. scabra e E. polita. Ao se utilizar o algoritmo morfológico para confirmação específica, calculou-se o índice algorítmico de E. neodebliecki (G2 = $1,29 \pm 0,05$ e $\mathrm{SP}=1,62 \pm 0,35)$, o qual ainda não havia sido estabelecido.
\end{abstract}

Palavras-chave: Eimeria, suínos, Campos dos Goytacazes, criação rústica, análise morfométrica, algoritmos morfológicos.

\begin{abstract}
This article aimed at to identify and to compare three Eimeria species isolated from swines in the municipality of Campos dos Goytacazes based on the traditional morphology and on an morphologic algorithm previously proposed. The animals whose feces were colleted did not show any clinical signs of eimeriosis. The oocysts found in swine feces were visually separated into three types and its lengths and widths were measured to identification of their species. Morphology and means were similar to those from E. neodebliecki, E. scabra and E. polita oocysts. Moreover, it was used a morphologic algorithm to confirm the species found; however, $E$. neodebliecki algorithmic index ( $G 2=1,29 \pm 0,05$ e SP $=1,62 \pm 0,35$ ) has not been established yet.
\end{abstract}

Keywords: Eimeria, pigs, Campos dos Goytacazes, rustic breeding, morphometric analysis, morphologic algorithms.

\section{Introdução}

Espécies de Eimeria têm sido associadas à diarréia e lesões intestinais em suínos de diversos países (Davies et al., 1963). As espécies do gênero Eimeria são freqüentemente encontradas nas fezes de suínos, no entanto, pelo seu baixo potencial em induzir sintomatologia clínica aparente, estas são pouco evidenciadas quanto a estudos mais detalhados sobre suas infecções (Ernst, 1987; Lindsay et al., 1987; Koudela e Vítovec, 1992). Entretanto, a eimeriose clínica em suínos já foi relatada em estudos experimentais e de campo, comprovando sua implicação patológica (Vítovec et al., 1987; Vítovec e Koudela, 1990; Henry e Tokach, 1995), podendo causar diminuição do crescimento e conseqüente perdas econômicas, mesmo em caráter subclínico (Pellérdy, 1974).

Os oocistos deste gênero em suínos são difíceis de se identificar quanto à respectiva espécie em razão das consideráveis alterações morfológicas encontradas em amostras de uma mesma espécie (Imarom, 1997).

Recentemente, foi formulado um sistema de identificação de oocistos do gênero Eimeria, utilizando-se algoritmos para distinção das espécies que acometem suínos. Para tanto, utilizou-se a diferenciação dos oocistos entre os que possuem parede externa fina e grossa, bem como, a atribuição de fatores para a coloração e para a forma dos oocistos. As medidas do diâmetro maior dos oocistos e esporocistos e do diâmetro menor dos esporocistos também foram utilizadas neste sistema de identificação (Dauschies et al., 1999).

O objetivo do presente trabalho foi identificar as espécies do gênero Eimeria com base na morfometria dos oocistos encontrados nas fezes de suínos criados em condições rústicas no município de Campos dos Goytacazes, estado do Rio de Janeiro, e de se proceder à análise a partir de algoritmo morfológico atualmente proposto.

\footnotetext{
* Sob os auspícios do CNPq.

** Curso de pós-graduação em Ciências Veterinárias da UFRuralRJ. paulorcf@ufrrj.br, fvmassad@ufrrj.br

*** Departamento de Parasitologia Animal, Instituto de Veterinária - UFRuralRJ. BR 465 Km 7 - 23890-000 Seropédica, RJ, Brasil. lopescwg@ufrrj.br, leira@ufrri.br

*** Laboratório de Sanidade Animal, CCTA, UENF. Campos dos Goytacazes, RJ, Brasil. foliveira@uenf.br
} 


\section{Material e métodos}

O estudo foi realizado a partir de coletas de material de uma pequena propriedade do município de Campos dos Goytacazes, mesorregião norte-fluminense. Realizou-se visita a esta propriedade, onde os piquetes se localizavam em uma área não-cimentada. A alimentação dos animais era baseada em restos alimentares e a água ofertada aos animais não apresentava condições visualmente satisfatórias. Não havia separação do plantel em relação a suas faixas etárias.

As fezes foram coletadas direto do reto dos animais adultos e dos leitões logo após a defecação. O material fecal coletado foi acondicionado em recipientes de vidro esterilizados contendo bicromato de potássio a $2,5 \%$ na proporção mínima de $1: 3$ e levadas ao Laboratório de Coccídios e Coccidioses, Projeto Sanidade Animal (Embrapa/UFRuralRJ), no Departamento de Parasitologia Animal da UFRuralRJ, município de Seropédica, estado do Rio de Janeiro.

No laboratório, foi executado exame de centrífugo-flutuação das fezes em solução saturada de açúcar (gravidade específica $=1,25 \mathrm{~g} / \mathrm{L}$ ) conforme metodologia desenvolvida previamente por Figueiredo (1982), onde se identificaram oocistos não-esporulados de coccídios da família Eimeriidae. Após isto, a solução fecal foi posta a esporular em dicromato de potássio a $2,5 \%$ em placas de Petri à temperatura ambiente.

Após completada a esporulação, em um intervalo de 10 dias, foram repetidos exames de centrífugo-flutuação com solução saturada de sulfato de magnésio, tendo sido substituída a solução saturada de açúcar com o objetivo de interferir o mínimo possível na morfometria dos oocistos. Utilizou-se centrífuga Excelsa 3 (Fanem Ltda.® Modelo $204 \mathrm{~N}$ - São Paulo, Brasil) a 600 G durante 10 minutos para então proceder-se a uma segunda centrífugo-flutuação. Após certificar-se de que se tratava de oocistos do gênero Eimeria, estes então foram separados morfologicamente em três espécies, onde 20 exemplares de cada foram medidos considerando-se os diâmetros maior e menor dos oocistos e esporocistos.

A diferenciação morfológica, base para análise morfométrica, foi feita conforme Vetterling (1965) utilizando-se microscópio óptico triocular Genaval Carl-Zeiss e ocular micrométrica GF$\mathrm{P} 16 \mathrm{x}$. Os dados foram armazenados e analisados utilizandose os programas Excel for Windows ${ }^{T M}$ versão 2000 e GraphPad Instat ${ }^{\mathrm{TM}}$, com base no teste t de "Student".

Para ratificação das espécies já identificadas, foi utilizado o algoritmo morfológico proposto por Dauschies et al. (1999) para oocistos de Eimeria parasitos de suínos.

Diâmetro maior

\section{Resultados e discussão}

Não houve sinais clínicos relativos a eimeriose nos animais examinados, apesar dos mesmos acharem-se em estado corporal ruim. Este achado pode ser creditado a fatores inespecíficos relacionados com a falta de manejo técnico, higiene e alimentação adequada.

Por meio da análise morfométrica dos oocistos esporulados e dos esporocistos encontrados nas fezes dos suínos, foram identificadas as espécies E. neodebliecki, E. scabra e E. polita (Tabela 1), as quais não haviam sido relatadas para a região e o sistema de criação estudados. Quanto aos índices morfométricos, E. neodebliecki e E. polita foram semelhantes aos resultados obtidos por Vetterling (1965), enquanto para E. scabra, a média dos índices morfométricos se situou entre o intervalo de 1,20 a 1,83 .

No entanto, quando se utilizou o algoritmo proposto por Dauschies et al. (1999), os resultados obtidos não foram

Tabela 1: Características morfométricas dos oocistos das três espécies de Eimeria identificadas no presente estudo

\begin{tabular}{lccc}
\hline \hline & E. neodebliecki & E. scabra & E. polita* $^{*}$ \\
\cline { 1 - 1 } OOCISTOS $^{1}$ & & & \\
\cline { 1 - 1 } Diâmetro maior & $21,75 \pm 2,76^{\mathrm{NS}}$ & $32,38 \pm 0,49^{\mathrm{NS}}$ & $29,62 \pm 2,28^{\mathrm{NS}}$ \\
Diâmetro menor & $15,84 \pm 1,79^{\mathrm{NS}}$ & $24,56 \pm 1,14^{\mathrm{S}}$ & $22,06 \pm 2,11^{\mathrm{NS}}$ \\
Índice morfométrico & 1,34 & 1,32 & 1,36 \\
Forma & Elipsóide & Ovóide & Elipsóide \\
Tipo de parede & Delgada & Espessa & Espessa
\end{tabular}

Amarelada a amarronzada

Incolor a amarelada

ESPOROCISTOS ${ }^{1}$

Diâmetro menor

* Sinonímia: E. cerdonis.

Número de medições igual a 20.

Não-significativo quando comparado às medições de Vetterling (1965) ao teste t de "Student". Significativo com pd"0,0001 quando comparado às medições de Vetterling (1965) ao teste t de "Student".

semelhantes aos aqui descritos (Tabela 2), possivelmente porque o desvio-padrão obtido pelas análises destes autores não foi suficientemente adequado para abranger espécimes que, mesmo pertencentes a uma determinada espécie do gênero Eimeria, poderiam guardar pequenas diferenças morfométricas características de indivíduos isolados geograficamente. Isto vai a favor da citação de Imarom (1997), que postulou que oocistos de Eimeria, mesmo de uma mesma espécie, podem ter diferenças morfométricas consideráveis de um para o outro, caracterizando assim o pleomorfismo entre os oocistos eliminados. Ainda, é possível que os valores para os algoritmos encontrados por Dauschies et al. (1999) sejam muito restritos à população de oocistos eliminados por suínos alocados na área do estudo original e que estes não poderiam ser completamente extrapolados para oocistos de Eimeria eliminados por suínos nas demais regiões do mundo. 
Tabela 2: Comparação morfométrica dos oocistos das três espécies de Eimeria identificadas no presente estudo utilizando-se o algoritmo proposto por Daugschies et al. (1999)

\begin{tabular}{ccccc}
\hline \hline & & E. neodebliecki & E. scabra & E. polita \\
\hline \multirow{4}{*}{ Presente estudo } & G1 & IC & $3,16 \pm 0,05^{\mathrm{A}}$ & $2,34 \pm 0,12^{\mathrm{A}}$ \\
& G2 & $1,29 \pm 0,05$ & IC & IC \\
& SP & $1,62 \pm 0,35$ & IC & IC \\
Daugschies et al. & G1 & IC & $3,46 \pm 0,37^{\mathrm{B}}$ & $2,75 \pm 0,09^{\mathrm{B}}$ \\
(1999) & G2 & $*$ & IC & IC \\
& SP & $*$ & IC & IC \\
\hline \hline
\end{tabular}

* Os autores não obtiveram medições desta espécie em seu trabalho.

A, B Letras diferentes em uma mesma coluna significam diferença significativa com pd"0,0001 ao teste t de "Student".

IC: Impossível calcular.

G1. Algoritmo para oocistos de parede espessa.

G2 e SP. Algoritmos para oocistos de parede delgada.
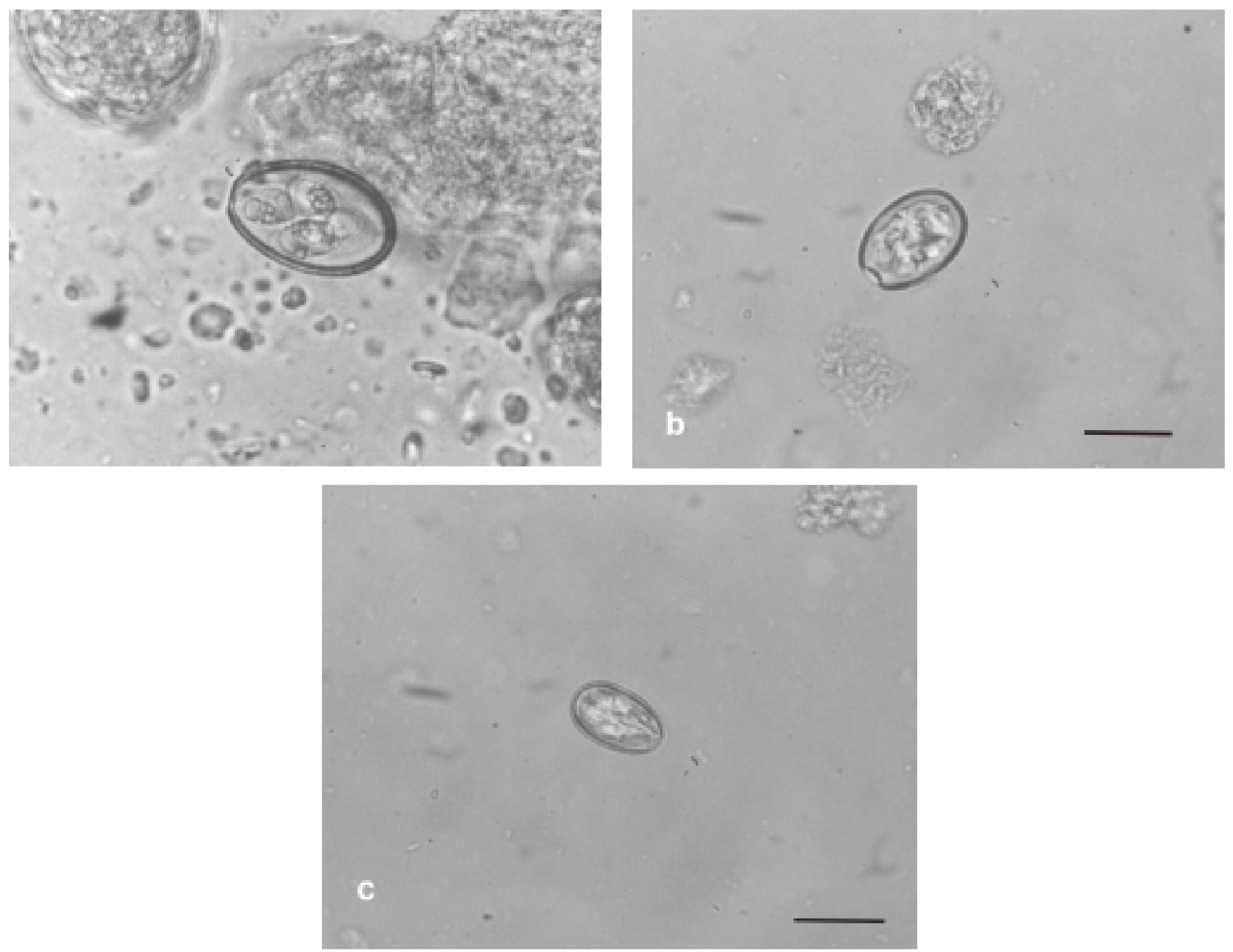

Figura 1: Oocistos esporulados do gênero Eimeria parasitos de suínos em solução saturada de açúcar. a) E. scabra. b) E. polita. c) E. neodebliecki. $=20 \mu \mathrm{m})$ 


\section{Referências}

DAUGSCHIES, A.; IMAROM, S.; BOLLWAHN, W. Differentiation of porcine Eimeria spp. by morphologic algorithms. Vet. Parasitol., v. 81, p. 201-210, 1999.

DAVIES, S. F. M.; JOYNER, L. P.; KENDALL, S. B. Coccidiosis, Oliver and Boyd, London, 1963.

ERNST, J. V. Pathogenicity in pigs experimentally infected with Eimeria spinosa. J. Parasitol., v. 73, p. 1254-1256, 1987.

FIGUEIREDO, P. C. Infecções naturais por eimerias em bovinos de raças leiteiras no Estado do Rio de Janeiro. 83p. Dissertação (Mestrado) - curso de pós-graduação em Medicina Veterinária (Parasitologia Veterinária)-Universidade Federal Rural do Rio de Janeiro. Itaguaí, RJ, 1982.

HENRY, S.C.; TOKACH, L. M. Eimeria-associated pathology in breeding gilts. Swine Health Prod., v. 3, p. 200-201, 1995.

IMAROM, S. Untersuchungen zur Ausscheidung von Eimerienoozysten durch Sauen im Laufe eines Fortpflanzungszyklus. Vet. Med. Diss., Hannover, Germany, 1997.
KOUDELA, B.; VÍTOVEC, J. Biology and pathogenicity of Eimeria spinosa (Henry, 1931) in experimentally infected pigs. Int. J. Parasitol., v. 22, p. 651-656, 1992.

LINDSAY, D. S.; BLAGBURN, B. L.; BOOSINGER, T. R. Experimetal Eimeria debliecki infections nursing and weaned pigs. Vet Parasitol., v. 25, p. 39-45, 1987.

PELLÉRDY, L. P. Coccidia and Coccidiosis. Verlag Paul Parey, Berlin, Hamburg, 959 p. 1974.

VETTERLING, J. M. Coccidia (Protozoa: Eimeriidae) of swine. J. Parasitol., v. 51, p. 897-912, 1965.

VÍTOVEC, J.; KOUDELA, B. Pathology and ultrastructural pathology of Eimeria debliecki (Douwes, 1921) in experimentally infected pigs. Fol. Parasitol., v. 37, p. 193-199, 1990.

VÍTOVEC, J.; KOUDELA, B.; STERBA, J. Pathology and pathogenicity of Eimeria scabra (Henry, 1931) in experimentally infected pigs. Fol. Parasitol.; v. 34, p. 299-304, 1987. 